\title{
EVIDENCE FOR A TILL LAYER BENEATH STORGLACIÄREN, SWEDEN, BASED ON ELECTRICAL RESISTIVITY MEASUREMENTS*
}

\author{
By GeofF Brand, \\ (Department of Geology and Geophysics, University of Minnesota, Minneapolis, \\ Minnesota 55455, U.S.A.) \\ VEIJO POHJOLA, \\ (Department of Physical Geography, University of Uppsala, Uppsala, Sweden) \\ and Roger LeB. HoOKe \\ (Department of Geology and Geophysics, University of Minnesota, Minneapolis, \\ Minnesota 55455, U.S.A.)
}

\begin{abstract}
Electrical resistivity measurements were made in a series of closely spaced holes drilled to the base of Storglaciären. Electrodes were lowered to the bottoms of the holes where they made contact with the substrate beneath the glacier. The measurements show that a layer of till, $\sim 0.4-0.7 \mathrm{~m}$ thick, is present at the base of the glacier. The low resistivity of the layer indicates that it has a high water content, compared with tills of similar composition in the pro-glacial environment. A marked reduction in resistivity after a heavy rain storm demonstrates that the water content is sensitive to variations in water input at the surface.
\end{abstract}

\section{INTRODUCTION}

Storglaciären (Fig. 1) is a small, predominantly temperate valley glacier in northern Sweden that has been studied since Schytt $(1959,1966,1968)$ began the stillcontinuing mass-balance measurements on it in the spring of 1946. Recent work has included velocity measurements over periods as short as one day (Hooke and others, 1983; unpublished data), bore-hole deformation surveys (Hooke and others, 1987; paper in preparation by V. Pohjola and R. LeB. Hooke), sensitive strain and tilt measurements (paper in preparation by P. Jansson and R. LeB. Hooke), waterbalance studies (Östling and Hooke, 1986), and dye-trace experiments (Hooke and others, in press; Seaberg and others, in press).

The purpose of the present study was to determine the nature of the substrate beneath the glacier near the middle of the ablation area, using geoelectrical techniques. To circumvent problems posed by the highly resistive ice cover, the measurements were made in a series of bore holes that penetrated to the base of the glacier (Fig. 1). This technique was pioneered by Haeberli and Fisch (1984). Radio-echo soundings (Björnsson, 1981) indicated that the ice was between 120 and $140 \mathrm{~m}$ thick in the area chosen.

*Publication No. 1107 of the School of Earth Sciences, Department of Geology and Geophysics, University of Minnesota, Minneapolis, Minnesota 55455, U.S.A.

\section{THE GEOELECTRIC METHOD}

Standard procedures for resistivity-sounding experiments are described in any geophysical prospecting textbook (e.g. Dobrin, 1976). Only a short overview will be given here.

In the resistivity method, either a direct current or an alternating current of very low frequency is applied to the ground by two electrodes, commonly referred to as the current electrodes. The potential conditions of the surface depend on the conductivity of the material beneath it. By measuring the potential difference between two additional electrodes, commonly referred to as the potential electrodes, a quantity known as the apparent resistivity, $\rho_{\mathrm{a}}$, can be determined from $\rho_{\mathrm{a}}=K V / I$ where $K$ is a geometric factor, defined later, $V$ is the voltage difference, and $I$ is the total current. $\rho_{\mathrm{a}}$ has the units of resistance times length and is most commonly given in ohm meters. By moving the current electrodes further apart, deeper layers of material gradually have a greater influence on the value of $\rho_{\mathrm{a}}$. The actual resistivity of a layer, $\rho$, can be calculated from the apparent resistivity.

\section{PROCEDURE}

Measurements conducted on the surface of a glacier would not reveal useful information on the subglacial bed characteristics because temperate or near-temperate ice is extremely resistant. Röthlisberger (1967, p. 604), for example, reported values of $\rho>10^{7} \mathrm{ohm} \mathrm{m}$ from several temperate glaciers, and $\mathrm{King}$ and others (in press) obtained values of $3-4 \times 10^{7} \mathrm{ohm} \mathrm{m}$ from measurements on Storglaciären. The ice thus shields the deeper material. To overcome this problem, a number of holes were drilled to the base of the glacier using hot-water drilling techniques (Iken and others, 1977). By lowering electrodes down these holes, direct contact with the ice-bed interface was possible. Because the resistivity of glacial ice is so high, it can be assumed that the current entering it is negligible. The analysis can thus be conducted as if the geometry were an electrical half-space, similar to an air-rock interface.

To determine whether a particular bore hole reached the bottom, a simple electrical measurement was taken. The equipment used for this purpose, as well as in all other 


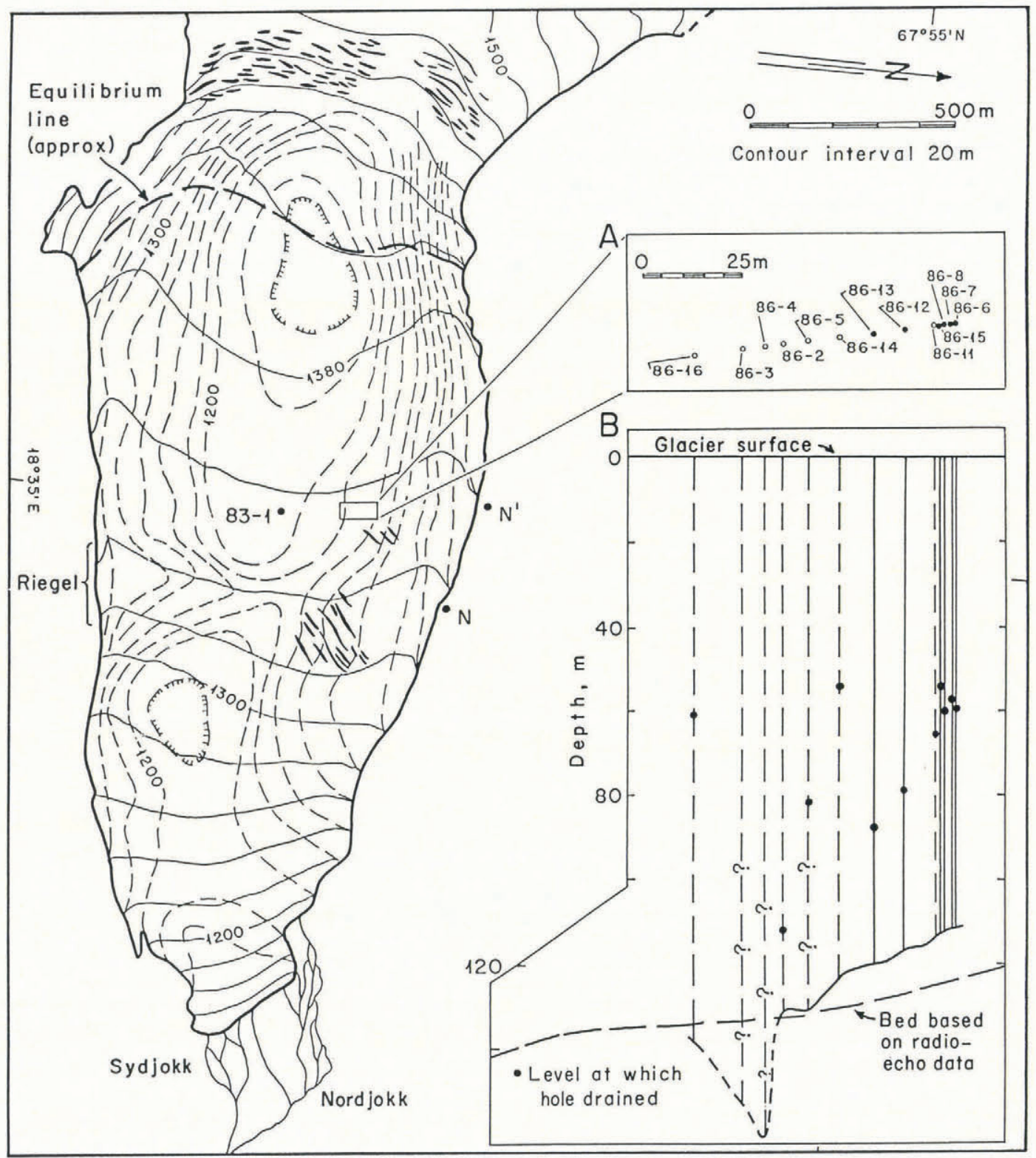

Fig. 1. Map of the lower part of Storglaciären showing surface and bed topography. Locations of bore holes are shown in inset $A$, and a cross-section along the line of holes is shown in inset B. Potential electrodes were in holes 86-6 and 86-7 at the far right in inset $B$. Although current electrodes were emplaced in other holes, only those in holes shown with continuous lines were usable. Bottoms of holes 86-3 through 86-5 are queried in inset $B$ because it is known or suspected that they deviate significantly from the line of cross-section.

electrical measurements, was an ABEM Terrameter SAS $300 \mathrm{~B}$. A current was applied between the electrode being lowered down the hole and an electrode in the moraine $\sim 300 \mathrm{~m}$ north of the study area $\left(\mathrm{N}^{\prime}\right.$ in Fig. 1). Because glacier ice is an almost perfect insulator, the circuit was completed only when (and if) the electrode made contact with the subglacial material. (The fact that electrical contact was achieved only when the electrodes reached the bottoms of the holes, and not before, supports the assumption above that little current traveled through the ice itself.) Of 14 holes, ten were thus found to have reached bottom. Two of these refroze near the surface at times when electrodes were not in place. Electrodes were left permanently in place in the remaining eight, thus avoiding further problems with refreezing. Contact with the bottom was sporadic and unreliable in one of these (86-16; Fig. 1), however, and detailed inclinometry measurements in another (86-5) indicated that its bottom was displaced so far from the line of profile that it could not be used. Thus, of the holes drilled in 1986, only the six shown as solid lines in Figure 1 (inset B) were used in the experiment. A seventh hole (83-1; Fig. 1), drilled in 1983 and cased with aluminum tubing, was also used in one series of measurements (Fig. 2). The leads from the electrodes were gathered at a single point near the middle of the array so measurements could be made easily in a short period of time, even under adverse weather conditions.

Because the drilling was labor- and energy-intensive, the number of possible electrode placements was limited. This necessitated certain modifications of standard electrode arrangements. The half-Schlumberger arrangement (Orellano and Mooney, 1966) was found to be the most appropriate for the situation. In this arrangement, as applied herein, the potential electrodes were set in two of the bore holes, and one of the current electrodes was set in the moraine at N (Fig. 1), far enough away to be considered at infinity. The other current electrode was then moved to bore holes farther away from the potential electrodes. With this geometry, the geometrical factor $K$ is given by

$$
K=2 \pi M N\left[(L / M N)^{2}-1 / 4\right]
$$

where $M N$ is the spacing between the potential electrodes 
and $L$ is the distance from the moving current electrode to the midpoint between the two potential electrodes.

The thickness of any conducting layer can be determined if the minimum value of $L$ is of the same order as the layer thickness. The electrode spacing can then increase in a geometric progression (Fig. 1). As we expected that any till layer present would be thin, the potentia electrodes were placed in holes that were $1.0 \mathrm{~m}$ apart at the surface, and the closest current electrode was in a hole $2 \mathrm{~m}$ from the hole containing the nearest potential electrode. Thus, $L \simeq 2.5 \mathrm{~m}$ for this measurement. For measurements in the most distant hole (83-1) $M N$ was increased to $\sim 13 \mathrm{~m}$ Through rough inclinometry measurements and study of the internal consistency of the resistivity measurements, we established that the holes used were sufficiently straight that errors due to uncertainty in $M N$ and $L$ were negligible.

Each electrical measurement was averaged 16 times, first with the positive electrode at infinity and then with the negative electrode at infinity. These two values were then averaged. By means of this procedure, the influence of any natural telluric currents is cancelled. In each measurement we recorded a slight telluric current that was consistent in direction.

Before turning to the results, we point out that, although ice thicknesses determined by drilling were generally consistent with Björnsson's (1981) radio-echo measurements, holes $86-3$ and $86-4$ suggested the presence of a $25 \mathrm{~m}$ deep gorge about $10 \mathrm{~m}$ south of hole $86-5$. In view of the inclinometry results from hole $86-5$, however, we suspect that holes 86-3 and 86-4 may also have deviated significantly from vertical, and that this "gorge" is not real. Drilling techniques were modified after drilling hole $86-5$, so subsequent holes were straighter.

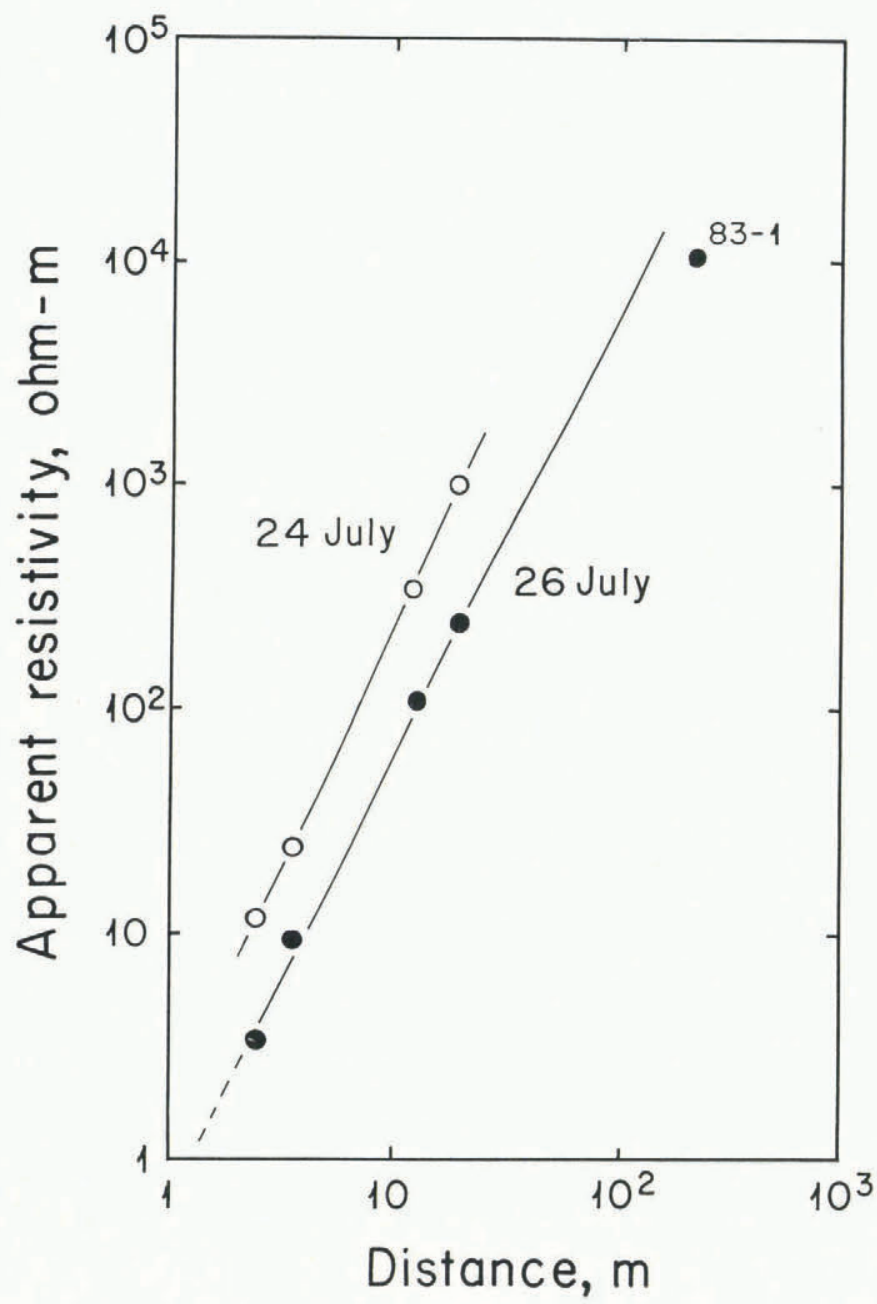

Fig. 2. Relation between apparent resistivity and distance between the center of the potential electrodes and the moveable current electrode. The slight change in slope between the 2 days is not believed to be significant.

\section{DISCUSSION}

Resistivity measurements were taken on 24 and 26 July 1986, and are plotted in Figure 2. The steep almost linear slopes of the lines in the plots indicate the presence of a thin layer of low-resistivity material, henceforth referred to as till, overlying a thicker layer with much higher resistivity. We assume that the latter is the amphibolite bedrock in the area. The resistivity of the amphibolite was measured in the pro-glacial environment and found to be $\approx 14000 \mathrm{ohm} \mathrm{m}$. As this is effectively infinite compared with the resistivity of the till, we can use the S-rule (Orellano and Mooney, 1966) to estimate the thickness of the latter: $\sim 0.7 \mathrm{~m}$. The slopes of the lines in Figure 2 are, however, somewhat steeper than is theoretically possible in a homogeneously layered medium. This suggests the presence of a lateral inhomogeneity of some kind. Southward thinning of the till or the presence of a topographic feature such as the "gorge" could have this effect. Analysis taking this into consideration (Fomina, 1958; Mooney, 1958; Kumar and Chowdary, 1977) results in an estimated thickness of only $\sim 0.35 \mathrm{~m}$. There is considerable uncertainty involved in making such estimates based on electrical resistivity measurements; among other things, the interpretations involve a subjective assessment of what is realistically possible. Thus, while we feel that these estimates of the layer thickness are of the right order of magnitude, we do not claim significantly greater precision.

There is a marked difference in resistivity between the two series of measurements. On $24 \mathrm{July}, \rho$ was $20 \mathrm{ohm} \mathrm{m}$ and on 26 July it was $3.5 \mathrm{ohm} \mathrm{m}$. Between these 2 days a rainfall of $23.3 \mathrm{~mm}$ occurred. Because the electrodes were permanently emplaced, changing conditions at the bed are the only explanation that can account for the change in $\rho$. This indicates that the physical character of the lowresistivity layer changes rapidly in response to changes in water input. Increases in water input apparently increase the water content of the layer, thus decreasing the resistivity.

At the bottoms of two of the bore holes, Lindstrand (unpublished) collected samples of water containing suspended sediment. The material was predominantly silt with as much as $20 \%$ clay and less than $5-10 \%$ sand. In bore hole $86-12$, a glob of compact clayey sediment was recovered on the bottom of the sampler. We infer that this was part of the bed itself. The composition of this material was found to be similar to that of the tills in front of the glacier. $\rho$ was also measured on these pro-glacial tills and found to be $\sim 500 \mathrm{ohm} \mathrm{m}$. The much lower resistivity of the subglacial till layer suggests that its water content was substantially higher.

\section{CONCLUSIONS}

Knowledge of bed characteristics is important in any glaciological research, whether it be focused on movement, sliding, erosion, or water flow. Resistivity-sounding experiments can provide valuable information on the nature of this material. Our measurements on Storglaciären strongly suggest that there is a layer of till, $\sim 0.4-0.7 \mathrm{~m}$ thick, beneath the experiment site. This layer probably extends to the moraine ( $\mathrm{N}$ or $\mathrm{N}^{\prime}$ ) to the north and may extend as far as hole $83-1$ to the south (Figs 1 and 2) but the resistivity data do not demonstrate this conclusively. The water content of this layer is high relative to the tills in front of the glacier, as indicated by the lower resistivities. The character of the layer adjusts rapidly to changes in water input.

Bore-hole deformation studies (Hooke and others, 1987; paper in preparation by V. Pohjola and R. LeB. Hooke) suggest that the glacier is decoupled from the bed in late July and August at the site of the present experiment, and also at two additional sites nearer the glacier center line. We infer that the till layer is deformable and that this is responsible for the decoupling at the site of the present experiment. By extension, we further infer that a till layer is probably also present at the other two sites. Dye-trace studies (Hooke and others, in press) and bore-hole waterlevel measurements (unpublished data) indicate that waterflow velocities through this part of the glacier, an area where the bed is markedly overdeepened (Fig. 1), are 
unusually low. Continuous conduits of substantial size probably do not exist. This leads us to believe that a subglacial layer of deformable till is probably present beneath a large fraction of the upper half of the ablation area.

\section{ACKNOWLEDGEMENTS}

We owe a warm debt of thanks to the late H. Mooney, teacher and colleague, without whose invaluable advice during the planning stages, this project could never have been completed in its present form. V. Chandler reviewed the paper carefully; his critical comments and those of W. Haeberli resulted in significant improvements. A. Fleetwood and W. Horn assisted with instrumentation. O. Lindstrand provided unpublished data. Our co-workers at Tarfala provided encouragement and assistance during the field work.

Financial support was provided by the University of Minnesota Undergraduate Research Opportunities Program, the U.S. National Science Foundation (grant DPP-8414190), the Swedish Natural Sciences Research Council, the Swedish Society of Anthropology and Geography, and the University of Stockholm.

\section{REFERENCES}

Björnsson, H. 1981. Radio-echo sounding maps of Storglaciären, Isfallsglaciären and Rabots glaciär, northern Sweden. Geografiska Annaler, Vol. 63A, Nos. 3-4, p. 225-31.

Dobrin, M.B. 1976. Introduction to geophysical prospecting. New York, McGraw-Hill.

Fomina, V.I. 1958. [Calculation of the effect of vertical and inclined boundaries in the interpretation of electrical soundings.] Prikladnaya Geofizika, Vyp. 20, p. 60-85. [English translation: Applied geophysics USSR. New York, Pergamon Press, 1962, p. 271-97.]

Haeberli, W., and Fisch, W. 1984. Electrical resistivity soundings of glacier beds: a test study on Grubengletscher, Wallis, Swiss Alps. Journal of Glaciology, Vol. 30, No. 106, p. 373-76.

Hooke, R. LeB., and others. 1983. Seasonal variations in surface velocity, Storglaciären, Sweden, by R. LeB. Hooke, J. Brzozowski, and C. Bronge. Geografiska Annaler, Vol. 65A, Nos. 3-4, p. 263-77.
Hooke, R. LeB., and others. 1987. Extrusion flow demonstrated by bore-hole deformation measurements over a riegel, Storglaciären, Sweden, by R. LeB. Hooke, P. Holmlund, and N.R. Iverson. Journal of Glaciology, Vol. 33 , No. 113 , p. $72-78$.

Hooke, R. LeB., and others. In press. Character of the englacial and subglacial drainage system in the upper part of the ablation area of Storglaciären, Sweden, by R. LeB. Hooke, S. Miller, and J. Kohler. Geological Society of America. Bulletin.

Iken, A., and others. 1977. Deep drilling with a hot water jet, by A. Iken, H. Röthlisberger, and K. Hutter. Zeitschrift für Gletscherkunde und Glazialgeologie, Bd. 12, Ht. 2, p. 143-56.

King, L., and others. In press. Comparison of resistivity and radio-echo soundings on rock glacier permafrost, by $\mathrm{L}$. King, W. Fisch, W. Haeberli, and H.P. Waechter. Zeitschrift für Gletscherkunde und Glazialgeologie.

Kumar, R., and Chowdary, M.V.R. 1977. Effect of vertical contact on Wenner resistivity soundings. Geophysical Prospecting, Vol. 25, No. 3, p. 471-80.

Lindstrand, O. Unpublished. Sedimenten frản Storglaciären, Kebnekaise; en kvalitativ bestämning. University of Göteborg, unpublished project report.

Mooney, H.M. 1958. A qualitative approach to electrical resistivity interpretation. Geofisica Pura e Applicata, Vol. 40, p. 164-71.

Orellano, E., and Mooney, H.M. 1966. Master tables and curves for vertical electrical sounding over layered structures. Madrid, Interscience.

Östling, M., and Hooke, R. LeB. 1986. Water storage in Storglaciären, Kebnekaise, Sweden. Geografiska Annaler, Vol. 68A, No. 4, p. 279-90.

Röthlisberger, H. 1967. Electrical resistivity measurements and soundings on glaciers: introductory remarks. Journal of Glaciology, Vol. 6, No. 47, p. 599-606.

Schytt, V. 1959. The glaciers of the Kebnekajse-massif. Geografiska Annaler, Vol. 41, No. 4, p. 213-27.

Schytt, V. 1966. Notes on glaciological activities in Kebnekaise, Sweden, during 1965. Geografiska Annaler, Vol. 48A, No. 1, p. 43-50.

Schytt, V. 1968. Notes on glaciological activities in Kebnekaise, Sweden during 1966 and 1967. Geografiska Annaler, Vol. 50A, No. 2, p. 111-20.

Seaberg, S.Z., and others. In press. Character of the englacial and subglacial drainage system in the lower part of the ablation area of Storglaciären, Sweden, as revealed by dye trace studies, by S.Z. Seaberg, J.Z. Seaberg, and R. LeB. Hooke. Geological Society of America. Bulletin. 